\title{
Site selection for Subtropical Thicket restoration: Mapping cold-air pooling in the South African sub-escarpment lowlands
}

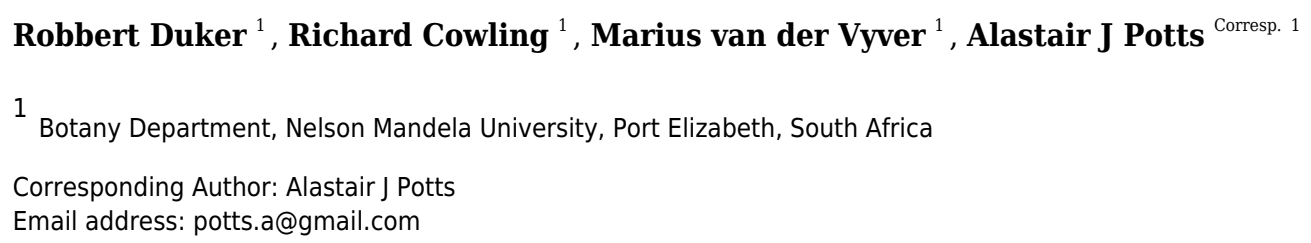

Restoration of Albany Subtropical Thicket in South Africa using the plant Portulacaria afra (an ecosystem engineer) has been hampered by selecting sites that are frost prone - this species is rather intolerant of frost. Identifying parts of the landscape that are exposed to frost may be challenging. Our aim is to calibrate an existing cold-air pooling (CAP) model to predict where frost is likely to occur in the valleys along the sub-escarpment lowlands where thicket is dominant. We calibrate this model using two valleys that have been monitored and during frost events. The calibrated model was then used to generate predictions of CAP for a further six valleys across the sub-escarpment lowlands. These predictions were then assessed using a qualitative visual comparison of existing treelines in six valleys - we observe a strong visual match between the predicted frost and frostfree zones with the subtropical thicket (frost-intolerant) and Nama-Karoo shrubland (frosttolerant) treelines. In addition, we tested the model output using previously established transplant experiments; 300 experimental plots were established across the landscape without consideration of frost events. Here we use a filtered subset of these plots $(n=70)$, and find that net primary production of $P$. afra was significantly lower in plots that the model predicted to be within the frost zone. We suggest using this calibrated model as part of the site selection process when restoring subtropical thicket in sites that lie within valleys, as it will greatly improve chances of restoration success in these environments. 


\section{Site selection for Subtropical Thicket restoration: Mapping}

\section{2 cold-air pooling in the South African sub-escarpment lowlands}

3 Robbert Duker ${ }^{1}$, Richard M. Cowling ${ }^{1}$, Marius L. van der Vyver ${ }^{1}$, Alastair J. Potts ${ }^{1}$

$4 \quad{ }^{1}$ Botany Department, Nelson Mandela University, South Africa.

5

6 Corresponding Author:

7 Alastair J. Potts ${ }^{1}$

8 Nelson Mandela University South Campus (Botany Department)

9 University Way

10 Summerstrand

11 Port Elizabeth

126001

13 Email address: $\underline{\text { Alastair.Potts@mandela.ac.za or potts.a@gmail.com }}$ 


\section{Abstract}

15 Restoration of Albany Subtropical Thicket in South Africa using the plant Portulacaria afra (an ecosystem engineer) has been hampered by selecting sites that are frost prone — this species is rather intolerant of frost. Identifying parts of the landscape that are exposed to frost may be challenging. Our aim is to calibrate an existing cold-air pooling (CAP) model to predict where frost is likely to occur in the valleys along the sub-escarpment lowlands where thicket is dominant. We calibrate this model using two valleys that have been monitored and during frost events. The calibrated model was then used to generate predictions of CAP for a further six valleys across the sub-escarpment lowlands. These predictions were then assessed using a qualitative visual comparison of existing treelines in six valleys — we observe a strong visual match between the predicted frost and frost-free zones with the subtropical thicket (frostintolerant) and Nama-Karoo shrubland (frost-tolerant) treelines. In addition, we tested the model output using previously established transplant experiments; 300 experimental plots were established across the landscape without consideration of frost events. Here we use a filtered subset of these plots $(\mathrm{n}=70)$, and find that net primary production of $P$. afra was significantly lower in plots that the model predicted to be within the frost zone. We suggest using this calibrated model as part of the site selection process when restoring subtropical thicket in sites

31 that lie within valleys, as it will greatly improve chances of restoration success in these 32 environments.

\section{Introduction}

35 Frost can hamper the restoration of plant communities (e.g. Snowcroft and Jeffrey 1999,

36 Snowcroft et al. 2000, Curran et al. 2010; Rorato et al. 2018). In this study, we calibrate a cold- 
37 air pooling (CAP) model to predict where frost may occur in the complex terrain of the sub-

38

escarpment lowlands of South Africa where Albany Subtropical Thicket is the dominant vegetation. We argue that mapping frost occurrence is crucial for thicket restoration, which primarily uses the frost-intolerant succulent shrub, Portulacaria afra (commonly known as “spekboom”; Fig. 1a).

Exposure to sub-zero temperatures can damage photosynthetic and metabolic activities in plants, and thereby reduce growth, reproduction, and/or survival (Osmond et al. 1987; Thomashow 1999; Holdo et al. 2006; Körner 2012a; Gusta and Wisniewski 2013). Thus, the distribution of plant species is commonly influenced by the occurrence of sub-zero temperatures at a variety of scales, ranging from broad regions to the local landscapes (Rouse 1984; Osmond et al. 1987; Körner 2012b; Wakeling et al. 2012; Duker et al. 2015a; 2015b; Muller et al. 2016). For example, alpine treelines — where tall woody vegetation is replaced by shorter shrubland — are vegetation boundaries driven by decreasing minimum temperatures associated with increasing elevation.(Körner 2012a). Frost has been suggested to be a driving determinant of treelines between the Albany Subtropical Thicket and Nama-Karoo biomes (hereafter referred to as "thicket" and "Karoo shrubland", respectively) (Duker et al. 2015a; 2015b). The frost-prone, continentally dry, and high-elevation interior plateau of South Africa is dominated by frosttolerant Karoo shrubland vegetation with small patches of thicket vegetation found in frost-free refugia such as steep slopes and rocky outcrops (Hoare et al. 2006; Mucina et al. 2006. Fig. 1b). However, this pattern is reversed in the sub-escarpment lowlands, which are lower and warmer but are prone to cold-air pooling (hereafter CAP; Fig. 1c). These lowlands are topographically complex due to the Cape Fold Mountains trending from west to east, intersected by rivers running, roughly, from north to south. In the valleys, the Karoo shrubland only occurs in frost- 
60 exposed valley floor, surrounded by dense thicket in the neighbouring frost-free valley slopes

61 (Duker et al. 2015a; 2015b). Frost occurs on the valley floor due to cold-air pooling (Schulze

62 2007; Duker et al. 2015a,b). When wind speeds are low or wind is absent, atmospheric buoyancy

63 forces can drive the formation of steep temperature gradients - this is caused by denser cooler

64 air decoupling from the free atmosphere and sinking below relatively more buoyant and warmer

65 air (Goulden et al. 2006; Lundquist et al. 2008; Dobrowski et al. 2009; Smith et al. 2010;

66 Dobrowski 2011). Such CAP in flat and low-lying areas is especially common in regions with

67 complex terrain, where changes in elevation and catchments result in intense frost on valley

68 floors while slopes remain frost-free (Barr and Orgill 1989; Neff and King 1989; Lindkvist et al.

69 2000; Chung et al. 2006; Bigg et al. 2014). This has led to the exclusion of taller, dense thicket

70 vegetation from valley floors where one would expect it to be dominant on the deeper

71 bottomland soils (Becker et al. 2015); this includes Portulacaria afra.

72 Portulacaria afra is an important species in the arid subtypes of the thicket biome, and is

73 considered an ecosystem engineer in this vegetation (van der Vyver et al. 2013). Here, its dense

74 growth form and high levels of litter production enriches the soil and provides shaded, relatively

75 moist microsites for the germination and establishment of woody thicket canopy species

76 (Sigwela et al. 2009; Wilman et al. 2014). This makes arid thicket particularly sensitive to

77 disturbances such as livestock browsing, which selectively removes the highly palatable

78 spekboom from the plant community - i.e. changing the microclimate that is critical for

79 persistence of other plant species. Historically high levels of livestock browsing — primarily by

80 goats or sheep - have removed much of the spekboom in arid thicket. This has resulted in loss of

81 ecosystem functioning and thicket biodiversity (Vlok et al. 2003; Lechmere-Oertel et al. 2005;

82 Lechmere-Oertel et al. 2008b; Sigwela et al. 2009). Subsequent colonization of species from the 
83 neighbouring Karoo shrubland is common (Hoffman and Cowling 1990; Rutherford et al. 2012).

84 Recently, large-scale initiatives have begun using clonal propagation of spekboom in areas of

85 livestock-degraded thicket, with the aim that this drought-hardy species will facilitate the

86 restoration of thicket ecosystems. A problem is that many areas of degraded thicket are now

87 physiognomically very similar to the Karoo shrubland, and this has meant that some restoration

88 efforts have mistakenly focused on frost-exposed parts of the landscape, specifically valley

89 floors. This significantly reduces survival and growth rates of spekboom (van der Vyver 2018).

90 Thus, a means to select frost-free sites is required where thicket restoration efforts are being

91 conducted in topographically complex landscapes.

92

93 To predict where frost events may occur in the landscape, we calibrated a cold-air pooling model 94 developed by Lundquist et al. (2008) for the subescarpment lowlands of South Africa; this model

95 was developed for high elevations $(>1000 \mathrm{~m})$ and latitudes $\left(>37^{\circ}\right)$ in the northern hemisphere.

96 Here we calibrate the model to terrain at lower elevations (generally $<1000 \mathrm{~m}$ ) at lower latitudes

$97\left(\sim 32-34^{\circ}\right)$ in the southern hemisphere. The CAP model uses a digital elevation model to generate 98 terrain characteristics (slope, relative elevation and curvature), and then threshold values are 99 applied to each of these to classify whether a part of the landscape is prone to CAP. This model 100 has been used to model CAP in other parts of the world (Curtis et al. 2014; Patsiou et al. 2017). 101 An alternative means to model CAP is to use physics-based modelling that simulates mesoscale 102 and finescale atmosphere flows. However, such high resolution simulations are computationally 103 expensive and need to be adjusted to each location they are applied (Pages et al. 2017).

104 Furthermore, such modelling is not necessarily superior in CAP prediction as they may not 105 always predict the extent and severity of cold-air drainage (Pages et al. 2017). 
106 We used two adjacent valleys in the southern sub-escarpment lowlands of South Africa that have

107 been well-studied in terms of CAP to calibrate the Lundquist et al. (2008) CAP model. We then

108 tested the calibrated CAP model using two approaches: 1) by visually comparing the model

109 predictions to the thicket-shrubland boundary in six valleys - as stated above, this boundary is

110 similar to an alpine treeline, but inverted with trees above the CAP frost zone; and 2) data from

111 the Thicket-Wide Plot experiment (an extensive transplant experiment conducted across the

112 thicket biome; further details provided in Materials and Methods) to determine if model

113 successfully predicts the decline in P. afra growth rates that would be associated with CAP in

114 mountainous areas and related frost occurrence, specifically in valley environments. Note that

115 this model predicts the CAP that occurs in complex terrain only (i.e. it cannot be used to predict

116 CAP in flat terrain).

\section{Materials \& Methods}

$118 \mathrm{R}$ version 3.3.1 was used to conduct all analyses ( $\mathrm{R}$ Core team 2016).

119 Region

120 The terrain of the coastal lowlands is particularly suited for producing CAP due to the

121 characteristic valley morphologies. The west-east trending Cape Folded Belt consists of erosion

122 resistant sandstones that form long parallel ranges with shales and small patches of Dwyka tillite

123 persisting on the lower slopes and valley floors; this gives rise to steep convex slopes with wide

124 flat valley bottoms (similar to the glacially carved U-shaped valleys in the Lundquist et al. 2008

125 study). The long parallel ranges are each fairly narrow (rarely more than $10 \mathrm{~km}$ wide), separated

126 by valleys that range in width (but usually not wider than $30 \mathrm{~km}$ ). The ranges are cut through by

127 very narrow defiles by rivers flowing from the Great Escarpment to the sea (i.e., roughly from 
128 north to south). The rugged ranges, open valley floors, with valley constrictions through

129 mountains increase the potential for CAP in this landscape.

130 Our approach, in brief, was to calibrate the CAP model (Lundquist et al. 2008) using two

131 adjacent valleys in the sub-escarpment lowlands where a range of CAP-related data have been

132 collected (e.g. during and after frost events, including temperature, transplant experiments and

133 survival, and field observations; Duker et al. 2015a,b). Next, we tested the model predictions at

134 six different localities — selected from satellite imagery (via Google Earth Pro) — using the

135 visually distinctive treeline between the thicket and Karoo shrubland. Finally, we tested our CAP

136 model by using productivity data of spekboom planted in the biome-wide thicket restoration

137 experiment. We describe each of these steps in detail below.

138 Cold air pooling model calibration

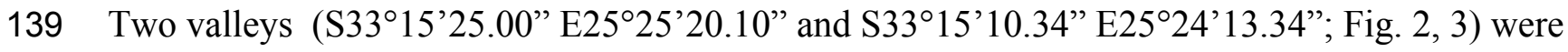

140 used for model calibration and frost-risk mapping. These sites were used because of the

141 availability of five years of temperature data (from July 2012 to October 2017), and many hours

142 of field observations during and after frost events (over 100 days spent on site spread across four

143 consecutive winters from 2013 to 2016). These "calibration valleys" are located in the Zuurberg

144 mountain range in the north-eastern portion of the Cape Fold Mountains. Temperature loggers

145 and field observations have confirmed that radiative frost $\left(0^{\circ} \mathrm{C}\right.$ at ground level) occured on valley

146 floors up to fifteen times each winter as a result of CAP on still and clear nights (detailed in

147 Duker et al. 2015a,b).

148 The first valley (Klipfontein) is $\sim 7.5 \mathrm{~km}$ long, $\sim 3 \mathrm{~km}$ wide and $\sim 300 \mathrm{~m}$ deep, whereas the second

149 valley (Buffels Nek) is $\sim 12 \mathrm{~km}$ long, $\sim 2.5 \mathrm{~km}$ wide, and $\sim 500 \mathrm{~m}$ deep (Fig. 3b,c). The vegetation 
150 patterns in these valleys consist of grassland and fynbos occupying the higher elevation

151 sandstone ridges, and thicket dominating the shale-derived soils on the lower valley slopes, and

152 Karoo shrubland occupying valley floors (which is a combination of shale- and alluvially-

153 derived soils). In these valleys, soil conditions (i.e. particle size, depth, infiltration rate, sodium

154 and electrical conductivity) are consistent across the valley floors and shale-derived sections of

155 the valley slopes (Becker et al. 2015). Nonetheless, Karoo shrubland replaces thicket on the

156 valley floor - this is largely driven by frost (Duker et al. 2015a,b). In these valleys, some of the

157 thicket-shrubland treelines are intact and clearly defined due to historically low levels of

158 livestock pressure (Ian Ritchie, farm manager, pers. comm., 2016); this boundary has become

159 blurred in places as livestock has removed thicket and Karoo shrubland species have invaded. In

160 such cases, frost-intolerant, but browser-tolerant, indicator species (e.g. Pappea capensis) were

161 used to identify the position of the treeline.

162

163 As outlined in the introduction, radiative frost on the southern African sub-escarpment lowlands

164 predominantly occurs on valley floors and in depressions, and is driven by cold-air pooling.

165 Following the Lundquist et al. (2008) model, and using the ALOS 30 m (Takaku et al. 2014)

166 digital elevation model (DEM), we generated the range of topographic characteristics - slope,

167 height relative to surrounding cells, and curvature - required to identify areas prone to CAP and 168 radiative frost (Fig. 4). Specifically, the Lundquist et al. (2008) model applies thresholds to maps 169 of slope, rank elevation, and curvature and combines these to generate a summary map

170 predicting where CAP should occur. Slope was calculated using the Horn (1981) algorithm in the 171 raster package (Hijmans \& van Etten 2012; Fig. 4). Rank elevation for each DEM grid cell (i.e., 172 percentile elevation relative to surrounding terrain) was determined by calculating it's 
173 topographic position within a given radius in the valley landscape — the radius was manually

174 calculated for each valley and is defined as half the distance between the two ridges that define

175 the valley in which the DEM grid cell is situated (Fig. 4). Specifically, we calculated the "rank

176 elevation of each DEM grid cell relative to the elevation of surrounding DEM grid cells within

177 the square with the specified radius in each cardinal direction from the DEM grid cell”

178 (Lundquist et al. 2008, p. 6). Calculating rank elevation in this way places each DEM grid cell

179 within the context of the broader landscape, i.e. valley, rather than the conventional approach

180 that only uses the immediate neighbouring cells for rank calculations.

181 The broad scale curvature was calculated using the Liston and Elder (2006) snow model formula:

$$
c v=\frac{1}{4}\left\{\frac{1}{2 r}\left(Z-\frac{Z w+Z e}{2}+Z-\frac{Z n+Z s}{2}\right)+\frac{1}{2 \sqrt{2 r}}\left(Z-\frac{Z s w+Z n e}{2}+Z-\frac{Z n w+Z s e}{2}\right)\right\}
$$

where $c v$ is the curvature at any particular DEM grid cell, $Z$ is the elevation of that DEM grid

cell, $r$ is the relevant radius for the landscape under investigation, $Z_{w / e / n / s}$ is the elevation a

distance $r$ to the west/east/north/south of the DEM grid cell, and $Z_{s w / n e / n w / s e}$ is the elevation a

distance $r$ to the south-west/north-east/north-west/south-east away from the DEM grid cell.

Again, the curvature calculated here does not use the cells immediately surrounding each DEM

grid cell, but is a derivative of the specific radius set by the user for the particular valley. Thus,

this determines whether a DEM grid cell is on a ridge or within a valley within the broader

surrounding landscape (Fig. 4). The curvature and rank elevation calculations used the same user-defined valley radius.

192 The Lundquist et al. (2008) CAP model was developed in the northern hemisphere (beyond

$\left.19337^{\circ} \mathrm{N}\right)$ - here we are applying this same approach in the southern hemisphere, where continental temperatures are ameliorated by the larger ocean area and in a region that is at least $3^{\circ}$ closer to the equator. The model thresholds used by Lundquist et al. (2008) had poor results when applied 
196 to the sub-escarpment coastal plains. Specifically, the model had a high degree of false positives

197 - i.e. it predicted cold-air pooling far upslope beyond the thicket-shrubland tree-line. This is

198 likely because the temperature gradients that form along these southern coastal lowlands are not

199 as steep as those experienced at the high elevation $(1000-3000 \mathrm{~m})$ and latitude $\left(37-40^{\circ} \mathrm{N}\right)$ study

200 areas of Lundquist et al. (2008). Therefore, we modified the threshold criteria based on

201 observations and data of known frost events in the calibration valleys. Thus, our calibrated

202 thresholds are to predict CAP are i) slope less than $10^{\circ}$ (originally: $<30^{\circ}$ in Lundquist et al.

203 (2008), ii) height relative to surrounding cells less than $30 \%$ (i.e. approximately the lower $1 / 3$ of

204 valleys; originally: $<50 \%$ ), and iii) cells with curvature values less than 0 (unchanged). These

205 modifications improved predictions, qualitatively assessed (i.e. a visual match up), of the

206 thicket-shrubland treeline at the two calibration valleys. Most importantly, it was observed that

207 frost only occurred in areas on the bottom of valleys, and in particular those with slope values

208 less than $10^{\circ}$ (the uppermost extent of the most extreme frosts). Visual matchups were conducted

209 by generating surface maps of frost risk (a binary no risk or high risk), exporting these as a .kml

210 file $(\mathrm{kml}$ package in R; Genolini et al. 2015) to Google Earth Pro, and comparing the CAP

211 predictions with existing vegetation boundaries evident in the imagery (Fig. 5.).

\section{Testing the calibrated CAP model}

213 We used two approaches to test the regionally-adjusted CAP model. First, we assessed its

214 accuracy in predicting the location of frost exposed areas in relation to thicket-shrubland treeline

215 in other valleys. Second, we tested the model predictions for a wide range of valleys against the

216 productivity of the frost-sensitive spekboom cuttings planted in the Thicket-Wide Plot

217 experiment (described below). 
218 Model prediction and treeline comparison

219 We assessed the model accuracy by visually by comparing the observed thicket-shrubland

220 treeline and predicted CAP boundary in six additional valleys located in sub-escarpment

221 lowlands of the Eastern Cape (Figs. S1-6). In two of these valleys, the treeline was readily

222 apparent (Figs. S1, S2), whilst in the other four valleys the treeline had been disturbed by

223 overbrowsing by domestic-livestock (Fig. S3, S4, S5, S6). In these valleys the historical treeline

224 was identified lay based on the visual persistence of clumps of thicket tree species (usually

225 Pappea capensis, Searsia cf. longispina). Visual assessment followed the same process as

226 described above (i.e. CAP predictions were exported to Google Earth Pro).

227 Model prediction and Thicket-Wide Plots

228 Data from the Thicket-Wide Plot (TWP) experiment were used to test the calibrated CAP

229 model. The TWP experiment was established in 2005 through collaboration amongst numerous

230 stakeholders including: the Subtropical Thicket Restoration Project (STRP), a community of

231 scientists, government departments, and thicket restoration practitioners. The primary aim of the

232 experiment was to inform best-practice restoration protocols. Different planting techniques were

233 tested to determine those that would maximise spekboom cutting survival and growth. Three

234 hundred $50 \times 50 \mathrm{~m}$ plots - fenced to exclude indigenous and domestic herbivores - were

235 established in the degraded state of spekboom-rich thicket, mapped as Spekboom Thicket and

236 Spekboomveld by Vlok et al. (2003). These plots spanned a wide variety of climatic and

237 topographic environments (Fig. 2). During the establishment phase of this experiment, the

238 potential of frost as a dominant driver of spekboom growth was not yet fully appreciated, and

239 thus the areas in which plots were established included valley floors - which may be frost-prone 
240 due to CAP. Thus, plots were positioned in landscapes in a climatically unbiased manner, and

241 thus offer an opportunity to investigate the effects of frost on thicket restoration success.

242 In each of the $50 \times 50 \mathrm{~m}$ plots, spekboom cuttings of various sizes were planted in different

243 treatments to identify the most effective methods for maximising survival and net primary

244 productivity (NPP) and ultimately stimulate thicket restoration (van der Vyver 2018). Here we

245 use the NPP rates calculated from only one of the treatments (to avoid treatment-related biases)

246 - specifically, cuttings of $50 \mathrm{~cm}$ in length and planted $15 \mathrm{~cm}$ deep - as this had the greatest

247 success rate. In brief, yearly rates of NPP for each plot was calculated through the use of

248 allometric sampling, where whole spekboom were harvested and their carbon content measured

249 with conventional methods. Specific details on the calculation of NPP rate are provided in the

250 Supplementary Information. Of the original 300 plots, only a subset were appropriate for testing

251 the CAP model. A plot was excluded if: 1) it occurred outside of a valley (where mapping CAP

252 would be inappropriate), 2) there was evidence of excessive herbivore browsing (by goats, sheep

253 or Greater kudu) due to a lack of fence maintenance, and 3) it occurred at an elevation $>1200 \mathrm{~m}$.

254 A plot was considered to be outside of a valley if peaks or ridges could not be identified within 8

$255 \mathrm{~km}$ of one another. We excluded plots above $1200 \mathrm{~m}$ as our CAP model was calibrated for the

256 sub-escarpment lowlands as we had existing data to conduct the calibration. At higher elevations,

257 there are steeper temperature gradients and thus another calibration exercise would be required

258 (with further data collection and field observations required).

\section{Results and Discussion}

260 To the authors' knowledge, this is the first application of a cold-air pooling (CAP) model in the

261 southern hemisphere. The predictions of calibrated CAP model successfully matched the thicket- 
262 shrubland treeline in additional testing valleys and the net primary productivity (NPP) was

263 significantly lower for Thicket-Wide Plots found in the predicted CAP zone.

\section{Vegetation boundaries in other valleys in the Eastern Cape}

265 This regionally calibrated model correctly identified the thicket-shrubland treeline at five of the 266 six test valleys (Fig. S1-6). Where valleys were deeper relative to their width, and had a steeper 267 change in gradient from the valley floors to valley slopes (i.e. Fig. S1, S2, S4, S5, S6), the CAP

268 (and thus frost presence) prediction aligned closely with the thicket-shrubland treeline.

269 However, where the valley was shallower (relative to its width, i.e. Fig. S3), the model predicted 270 a larger area covered by the CAP, and thus frost prone area, which extended $\sim 50 \mathrm{~m}$ further

271 upslope than the observed treeline between livestock degraded thicket and Karoo shrubland.

272 Nonetheless, in such cases this minor overprediction (false positives) will still assist in landscape

273 restoration planning to avoid planting in frost exposed areas. This predictive mapping of frost-

274 risk (via cold-air pool mapping) may be considered somewhat simplistic as it is based on

275 topographic features alone. Nonetheless, this approach does capture the areas in the landscape

276 that would likely be prone to frost, especially in more mountainous or valley areas such as the

277 Zuurberg mountain range. In addition, physics-based weather modelling has not been shown to

278 have greater accuracy at predicting frost events (e.g. Pages et al. 2017).

279 In geomorphologically simpler terrain, such as the wide flatland areas found between the Great

280 Escarpment and the Cape Fold Mountains, the CAP model as it is used here (in terms of the

281 thresholds for slope and broad landscape position) would not be suitable for predicting the

282 occurrence of frost. In these areas, where spekboom is locally dominant, weather station data and 
283 field observations would need to be collected to establish the areas within the landscape that frost

284 occurs, and its intensity under different weather conditions.

285 The Thicket-Wide Plot (TWP) experiment

286 Of the 70 TWPs selected for the analysis, 30 plots occurred in frost-prone areas and 40 were in

287 frost-free areas. Within this subset, spekboom planted in frost-free areas had significantly higher

288 levels (72.2\%) of mean aboveground net primary productivity relative to those situated in the

289 frost-prone areas $(U=720, p=0.046$; Fig. 6).

290 The Great Escarpment versus sub-escarpment coastal plains

291 The high elevation plateau of Southern Africa is a very different environment to the sub-

292 escarpment coastal plains. The climate in the interior is more continental than that of the coastal

293 plains, with corresponding lower mean and minimum temperatures, and lower rainfall. We have

294 observed that the topographic characteristics associated with frost on the high elevation plateau

295 of South Africa are different to those of the sub-escarpment plains. For example, frost occurs

296 higher up, and on steeper slopes, in the Mountain Zebra National Park of the Eastern Cape than

297 at the calibration valleys in the Zuurberg mountains and in more coastal areas, where it only

298 occurs on very flat ground (RD, pers. obs.). This Park is situated in the Sneeuberg Mountains on

299 the Great Escarpment of South Africa, at much higher elevations (approximately 1100-2000m)

300 and with greater topographic heterogeneity (deeper and wider valleys) and structures (flatter

301 mountaintops) than the calibration valleys in the Zuurberg mountains (400-900m).

302 Frost in the interior thus seems to have greater intensity on valley floors where minimum

303 temperatures can drop extremely low $\left(<-10^{\circ} \mathrm{C}\right)$, occurs much higher up valley slopes, and even

304 occurs on the high elevation plateaux on mountain tops. In this area, the size of frost-free refugia

305 where freezing-intolerant thicket species can survive are thus far smaller and isolated here than 
306 they along the sub-escarpment, where the majority of the landscape is frost-free. Thus, frost

307 characteristics differ substantially between the interior plateau and sub-escarpment lowlands.

308 Thus, the CAP-model thresholds reported here model we used to predict frost occurrence in the

309 sub-escarpment needs region-specific calibration (specifically slope and landscape-level

310 topographic position)

\section{Cold-air pooling and climate change}

312 CAP is decoupled from regional climate change (Curtis et al. 2014), so it is challenging to

313 predict how CAP-determined treelines will be influenced by warming average temperatures.

314 Thus, the effects of sub-zero temperatures may still affect the distribution of thicket at a regional

315 and elevational scale as fewer frost events occur, but treelines in CAP topography may or may

316 not be affected. This requires monitoring, both in simple and complex terrain. We suspect that

317 thicket treelines will be slow to respond to increasing suitable areas to grow as thicket dynamics

318 are exceptionally slow processes (Cowling et al. 2005, Wilman et al. 2014).

\section{Conclusions}

320 A basic recalibration of Lundquist et al. (2008) cold-air pooling (CAP) model demonstrates that

321 we can predict which areas are likely to be frost-prone. The reduced rates of aboveground net

322 primary productivity (NPP) in the TWP plots that were situated in frost-prone areas compared to

323 those in frost-free areas is a cause for major concern to restoration practitioners. Thus, we urge

324 that this model should be used to identify no-go areas during the site-selection process for

325 spekboom restoration.

326 Acknowledgements

327 Andre Bezuidenhout and Ian and Ritchie (Kaboega Farming) are sincerely thanked for their

328 provision of facilities, transport and accommodation that assisted with this study. 


\section{References}

331

332

333

334

335

336

337

338

339

340

341

342

343

344

345

346

347

348

349

350

Barr S, Orgill MM. 1989. Influence of external meteorology on nocturnal valley drainage winds. Journal of Applied Meteorology 28:497-517.

Becker CH, Coetsee C, Cowling RM, Potts AJ. 2015. The local landscape boundary between the Albany subtropical thicket and Nama-Karoo shrubland is not influenced by edaphic factors. South African Journal of Botany 101:107-111.

Bigg GR, Wise SM, Hanna E, Mansell D, Bryant RG, Howard A. 2014. Synoptic climatology of cold air drainage in the Derwent Valley, Peak District, UK. Meteorological Applications 21:161-170.

Chung U, Seo HH, Hwang KH, Hwang BS, Choi J, Lee JT, Yun JI. 2006. Minimum temperature mapping over complex terrain by estimating cold air accumulation potential. Agricultural and Forest Meteorology 137:15-24.

Cowling RM, Procheş Ş, Vlok JHJ. 2005. On the origin of southern African subtropical thicket vegetation. South African Journal of Botany 71:1-23.

Curran TJ, Reid EM, and Skorik C. 2010. Effects of a severe frost on riparian rainforest restoration in the Australian wet tropics: foliage retention by species and the role of forest shelter. Restoration Ecology 18:408-413.

Curtis JA, Flint LE, Flint AL, Lundquist JE, Hudgens B, Boydston EE, Young JK. 2014. Incorporating cold-air pooling into downscaled climate models increases potential refugia for snow-dependent species within the Sierra-Nevada Ecoregion, CA. PLoS ONE 9, e106984. 
351 Dayaram A, Harris LR, Grobler BA, van der Merwe S, Rebelo AG, Powrie LW, Vlok JHJ, 352 Desmet PG, Qabaqaba M, Hlahane K, Skwono AL. 2018. Vegetation map of South 353 Africa, Lesotho and Swaziland 2018: A description of changes since 2006. Bothalia

355 356 357 358 359 360 361 362 (Online) 49.

Dobrowski SZ, Abatzoglou JT, Greenberg JA, Schladow JG. 2009. How much influence does landscape-scale physiography have on air temperature in a mountain environment? Agricultural and Forest Meteorology 149:1751-1758.

Dobrowski SZ. 2011. A climatic basis for microrefugia: the influence of terrain on climate. Global Change Biology 17:1022-1035.

Duker R, Cowling RM, du Preez DR, Potts AJ. 2015. Frost, Portulacaria afra Jacq., and the boundary between the Albany Subtropical Thicket and Nama-Karoo biomes. South African Journal of Botany 101:112-119.

Duker R, Cowling RM, du Preez DR, van der Vyver ML, Weatherall-Thomas CR, Potts AJ. 2015. Community-level assessment of freezing tolerance: frost dictates the biome boundary between Albany Subtropical thicket and Nama-Karoo in South Africa. Journal of Biogeography 42:167-178.

Genolini C, Alacoque X, Sentenac M, Arnaud C. 2015. Kml and kml3d: R Packages to Cluster Longitudinal Data. Journal of Statistical Software 65:1-34.

Goulden ML, Miller SD, da Rocha HR. 2006. Nocturnal cold air drainage and pooling in a tropical forest. Journal of Geophysical Research 111: D08S04.

Gusta LV, Wisniewski M. 2013. Understanding plant cold hardiness: an opinion. Physiologia Plantarum 147:4-14. 
373 Hijmans RJ, van Etten J. 2012. raster: Geographic analysis and modelling with raster data. R 374 package version 2.0-12.

375 Hoare DB, Mucina L, Rutherford MC, Vlok JHJ, Euston-Brown DIW, Palmer AR, Powrie LW, 376 Lechmere-Oertel RG, Procheş Ş, Dold AP, Ward RA. 2006. Albany thicket biome Pages

377

378

379

380

381

382

383

384

385

386

387

388

389

390

391

392

393

394
540-583 in Mucina, L. and M. Rutherford editors. The vegetation of South Africa, Lesotho and Swaziland. South African National Biodiversity Institute, Pretoria, South Africa.

Hoffman MT, Cowling RM. 1990. Desertification in the lower Sundays River Valley, South Africa. Journal of Arid Environments 19:105-117.

Holdo RM. 2006. Elephant herbivory, frost damage, and topkill in Kalahari sand woodland savanna trees. Journal of Vegetation Science 17:509-518.

Horn BKP. 1981. Hill shading and the reflectance map. Proceedings of the Institute of Electrical and Electronics Engineers 69, 14-47.

Johnson MR, Anhaeusser CR, Thomas RJ. 2006. The geology of South Africa. Council for Geoscience (South Africa).

Körner C. 2012a. Alpine treelines: functional biology of the global high elevation tree limits. Springer, Basel.

Körner C. 2012b. Treeline climate. Pages 33-56 in C. Körner, editor. Alpine treelines: functional biology of the global high elevation tree limits. Springer, Basel.

Lechmere-Oertel RG, Kerley GIH, Cowling RM. 2005. Patterns and implications of transformation in semi-arid succulent thicket, South Africa. Journal of Arid Environments 62:459-474. 
395 Lechmere-Oertel RG, Kerley GIH, Mills AJ, and Cowling RM. 2008. Litter dynamics across 396 browsing-induced fenceline contrasts in succulent thicket, South Africa. South African $397 \quad$ Journal of Botany 74:651-659.

398 Lindkvist L, Gustavsson T, and Borgren J. 2000. A frost assessment method for mountainous 399 areas. Agricultural and Forest Meteorology 102:51-67.

400

401

402 403

404 405 406

407

408

409

410

411

412

413

414 415

416 417

Liston GE, Elder K. 2006. A meteorological distribution system for high-resolution terrestrial modelling (MicroMet), Journal of Hydrometeorology 7:217-234.

Lundquist JD, Pepin N, Rochford C. 2008. Automated algorithm for mapping regions of cold-air pooling in complex terrain. Journal of Geophysical Research 113:1-15.

MacDicken K. 1997. A guide to monitoring carbon storage in forestry and agroforestry projects (Arlington, VA: Winrock International).

Mucina L, Rutherford MC, Palmer AP, Milton SJ, Scott L, Lloyd W, van der Merwe B, Hoare DB, Bezuidenhout H, Vlok JHJ, Euston-Brown DIW, Powrie LW, Dold AP. 2006. Nama-Karoo biome. Pages 324-347 in Mucina, L. and M. Rutherford editors. The vegetation of South Africa, Lesotho and Swaziland. South African National Biodiversity Institute, Pretoria, South Africa.

Muller K, O’Connor TG, Henschel JR. 2016. Impact of a severe frost event in 2014 on woody vegetation within the Nama-Karoo and semi-arid savannah biomes of South Africa. Journal of Arid Environments 113:112-121.

Neff WD, King CW. 1989. The accumulation and pooling of drainage flows in a large basin. Journal of Applied Meteorology 28:518-529.

Oakes AJ. 1973. Portulacaria afra Jacq. - A potential browse plant. Economic Botany 27:413416. 
418 Osmond CB, Austin MP, Berry JA, Billings WD, Boyer JS, Dacey JWH, Nobel PS, Smith SD, 419 Winner WE. 1987. Stress physiology and the distribution of plants. BioScience 37:38-48.

420

421

422

423

424

425

426

427

428

429

430

431

432

433

434

435

436

437

438

439

440
Pagès M, Pepin N, and Miró JR. 2017. Measurement and modelling of temperature cold pools in the Cerdanya valley (Pyrenees), Spain. Meteorological Applications 24:290-302.

Patsiou TF, Conti E, Theodoridis S, and Randin CF. 2017. The contribution of cold air pooling to the distribution of a rare and endemic plant of the Alps. Plant Ecology \& Diversity $10: 29-42$.

R Core Team. 2016. R: Version 3.3.1. A Language and Environment for Statistical Computing. R Foundation for Statistical Computing, Vienna, Austria. URL https://www.Rproject.org/.

Rorato DG, Araujo MM, Tabaldi LA, Turchetto F, Griebeler AM, Berghetti ÁLP, and Barbosa FM. 2018. Tolerance and resilience of forest species to frost in restoration planting in southern Brazil. Restoration Ecology 26:537-542.

Rouse WR. 1984. Microclimate at arctic tree line 1. Radiation balance of tundra and forest. Water Resources Research 20:57-66.

Rutherford MC, Powrie LW, Husted LB. 2012. Plant diversity consequences of a herbivoredriven biome switch from Grassland to Nama-Karoo shrub steppe in South Africa. Applied Vegetation Science 15:14-25.

Schulze RE. 2007. South African atlas of climatology and agrohydrology. Water Research Commission, WRC Report 1489/1/06, Section 9.1. Pretoria, South Africa.

Sigwela AM, Kerley GIH, Mills AJ, Cowling RM. 2009. The impact of browsing-induced degradation on the reproduction of subtropical thicket canopy shrubs and trees. South African Journal of Botany 75:262-267.

Peer) reviewing PDF | (2019:08:40265:1:1:NEW 24 Feb 2020) 
441 Smith SA, Brown AR, Vosper SB, Murkin PA, Veal AT. 2010. Observations and simulations of 442 cold air pooling in valleys. Boundary-Layer Meteorology 134:85-108.

443 Snowcroft PG and Jeffrey J. 1999. Potential significance of frost, topographic relief, and Acacia 444 koa stands to restoration of mesic Hawaiian forests on abandoned rangeland. Forest $445 \quad$ Ecology and Management 114:447-458.

446 Snowcroft PG, Meinzer FC, Goldstein G, Melcher PJ and Jeffey J. 2000. Moderating Night 447 Radiative Cooling Reduces Frost Damage to Metrosideros polymorpha Seedlings Used for Forest Restoration in Hawaii. Restoration Ecology 8:161-169.

449

450

451

452

453

454 455 456

457

458 459

460

461

Takaku K, Tadono T, Tsutsui K. 2014. Generation of high resolution global DSM from ALOS PRISM. The International Archives of the Photogrammetry, Remote Sensing and Spatial Information Sciences XL-4:243-248.

Thomashow MF. 1999. Plant cold acclimation: freezing tolerance genes and regulatory mechanisms. Annual Review of Plant Physiology and Plant Molecular Biology 50:571599.

Van der Vyver ML, Cowling RM, Mills AJ, Difford M. 2013. Spontaneous return of biodiversity in restored subtropical thicket: Portulacaria afra as an ecosystem engineer. Restoration Ecology 21:736-744.

van der Vyver ML. 2018. Factors affecting effective ecological restoration of Portulacaria afra (spekboom)-rich subtropical thicket and aboveground carbon endpoint projections. $\mathrm{PhD}$ Thesis. Botany Department, Nelson Mandela University, Port Elizabeth, p. 167. (http://hdl.handle.net/10948/23250). 
462 Vlok JHJ, Euston-Brown DIW, Cowling RM. 2003. Acocks' valley bushveld 50 years on: new 463 perspectives on the delimitation, characterisation and origin of subtropical thicket $464 \quad$ vegetation. South African Journal of Botany 69: 27-51.

465 Wakeling JL, Cramer MD, Bond WJ. 2012. The savanna-grassland 'tree line': why don't 466 savanna trees occur in upland grasslands? Journal of Ecology 100:381-391.

467 Wilman V, Campbell EE, Potts AJ, Cowling RM. 2014. Is niche conservatism responsible for 468 environmental conditions that maximise germination of xeric subtropical thicket canopy 469 species? South African Journal of Botany 92:1-6. 


\section{Figure 1}

Portulacaria afra (spekboom), and the local- and regional treeline of thicket and Karoo shrubland

Fig.1. (A) Portulacaria afra (spekboom), (B) the local treeline of thicket and Nama-Karoo shrubland and $(\mathrm{C})$ the broader regional distribution of of the Albany Subtropical Thicket and Nama-Karoo shrubland biomes (DEM Takaku et al., 2014; Vegetation Dayaram et al., 2018). 


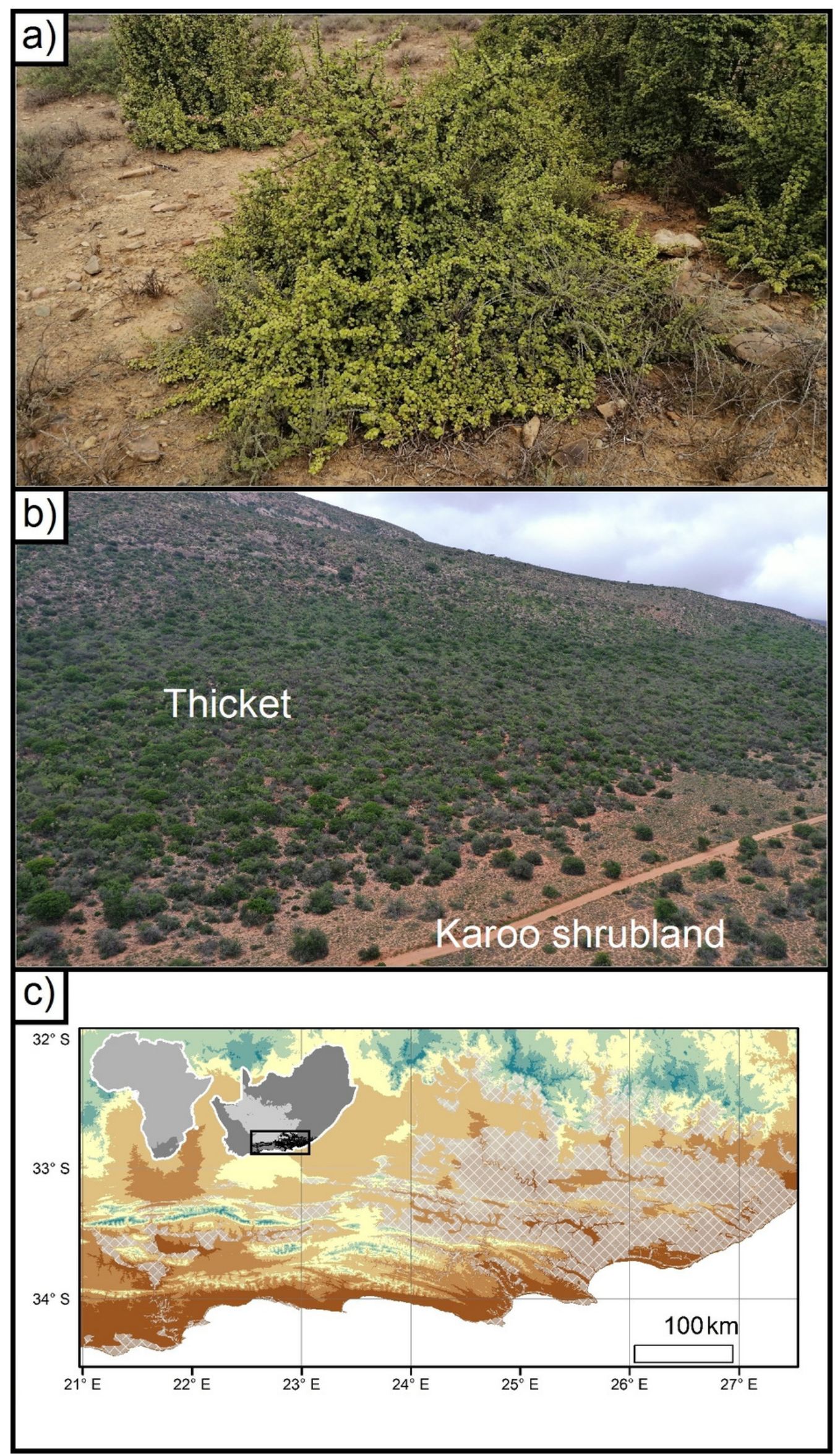

PeerJ reviewing PDF | (2019:08:40265:1:1:NEW 24 Feb 2020) 


\section{Figure 2}

Distribution of CAP model calibration and testing valleys and TWPs in relation to vegetation and elevation

Fig. 2. Digital Elevation Model (DEM; Takaku et al., 2014) of the study region, the occurrence of spekboom dominated thicket (Vlok et al., 2003), calibration and testing valleys, and the locations of each Thicket-Wide Plot (inside and outside CAPs) used in our study. Circles show location of the two calibration valleys. White-filled squares show location of the testing valleys. White-filled triangles show the location of the TWPs that were in CAP-prone areas. Black-filled triangles show the location of the TWPs that were in areas not prone to CAP.

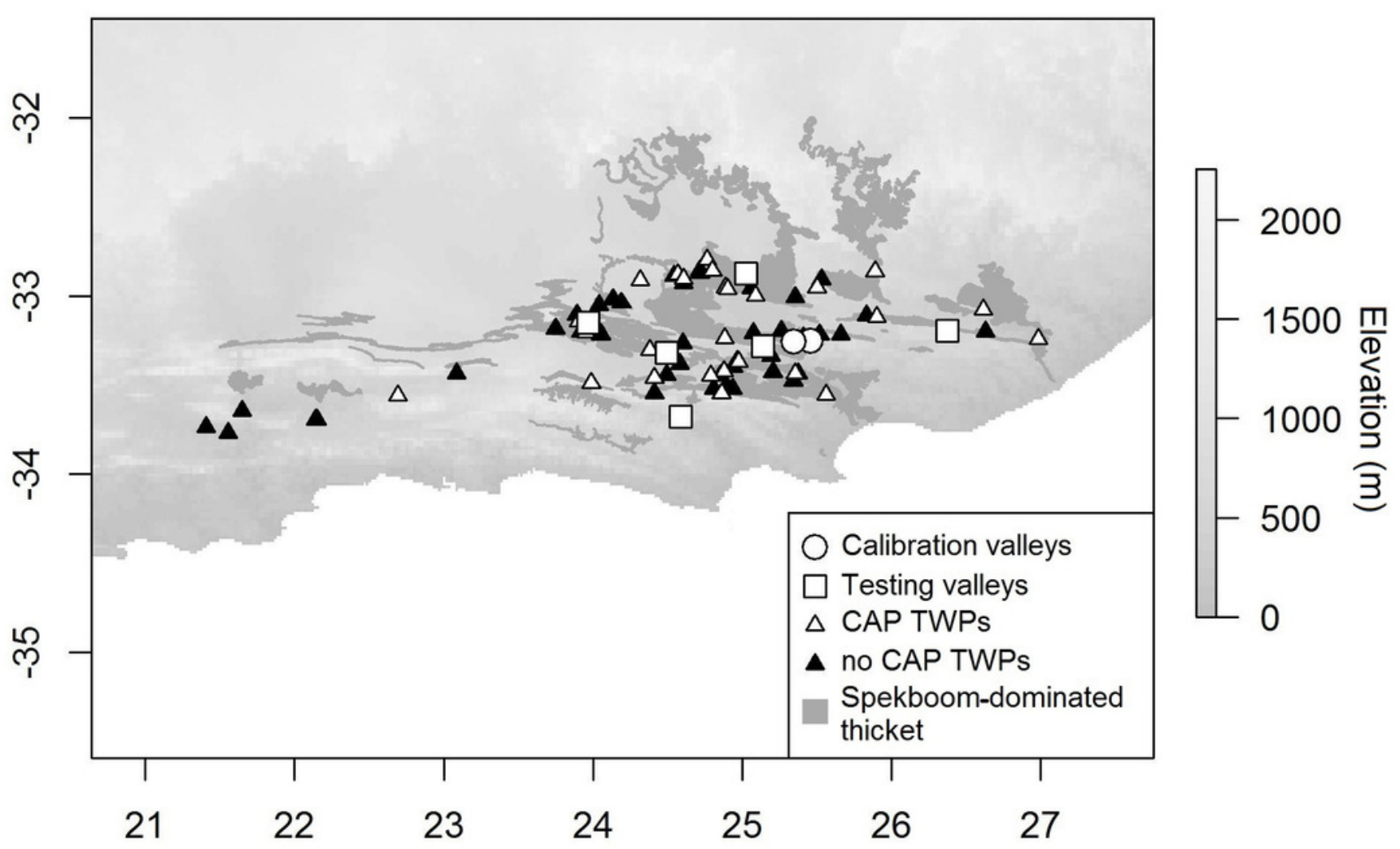




\section{Figure 3}

Model calibration valleys in the Zuurberg Mountains

Fig.3. The two frost model-calibration sites (Zuurberg Mountains) in the broader landscape

(A) and in demonstrating the thicket-shrubland boundary in both valleys (B: Buffels Nek; C: Klipfontein; source Google, 2019, Maxar Technologies, CNES/Airbus, AfriGIS, Landsat/Copernicus). Red lines indicate the valley diameters used to calculate radii. Grassland and fynbos vegetation is found on hill crests due to a variety of factors. Points indicate the position of temperature loggers in the landscape.

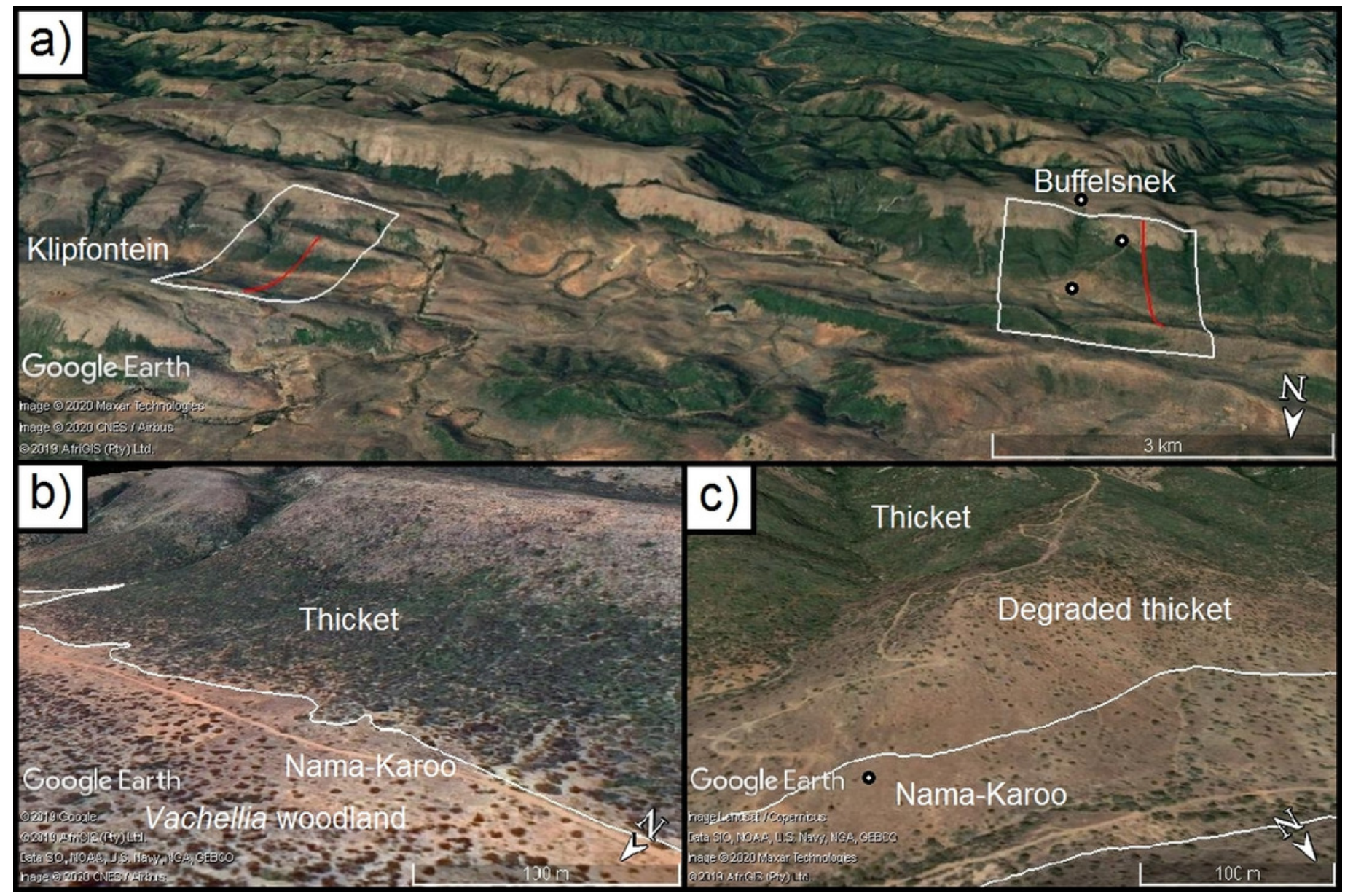


Figure 4

Surface maps of variables used to calculate CAP likelihood

Fig. 4. Maps of (A) elevation., (B) slope, (C) height relative to surroundings, (D) curvature for the Klipfontein valley in the western portion of the Kaboega study site (Takaku et al., 2014). 
a) Elevation (m)

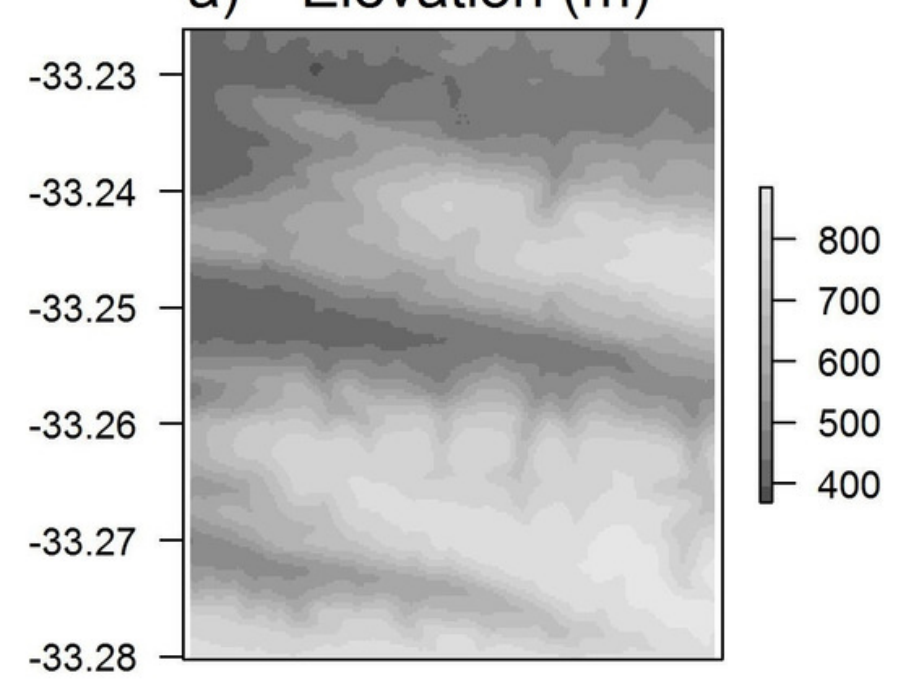

c) Relative height (\%)

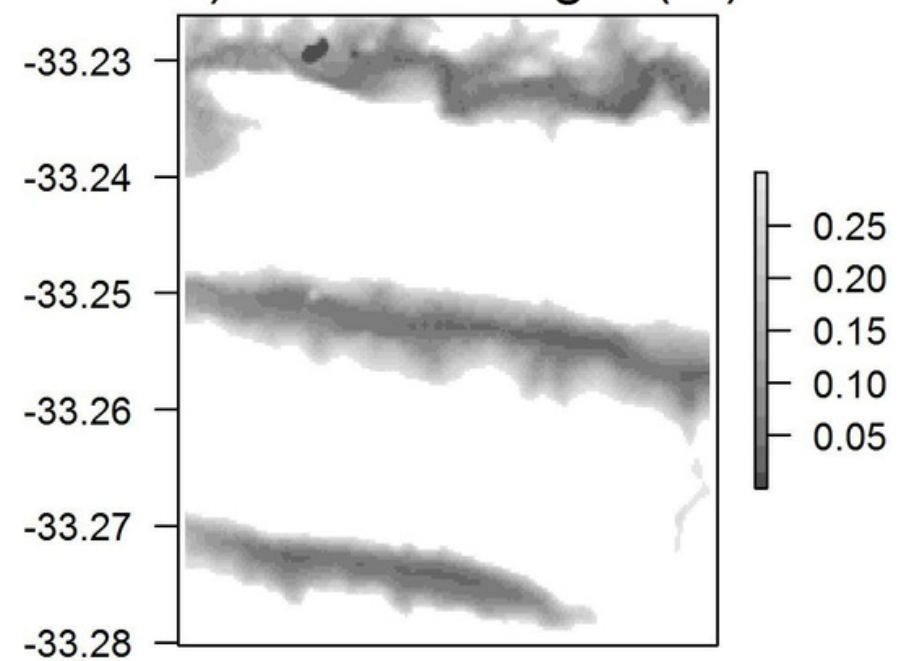

b) slope $\left({ }^{\circ}\right)$

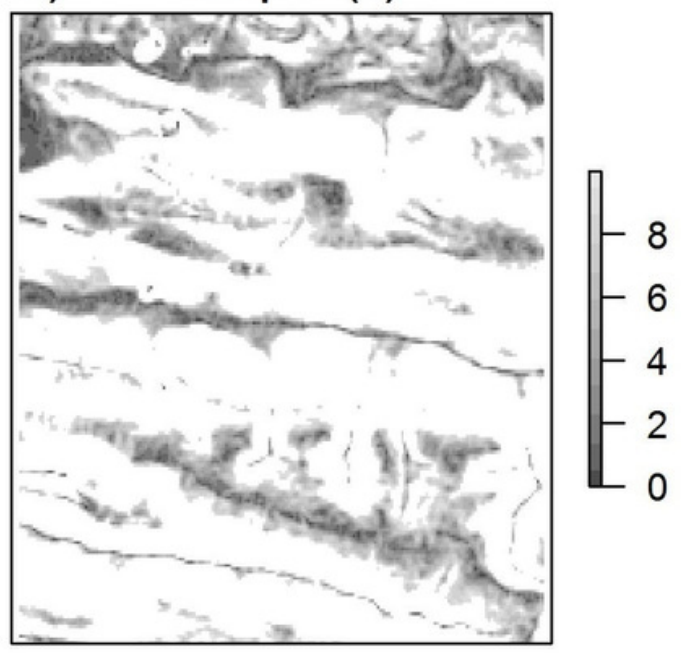

d) Curvature (dr)

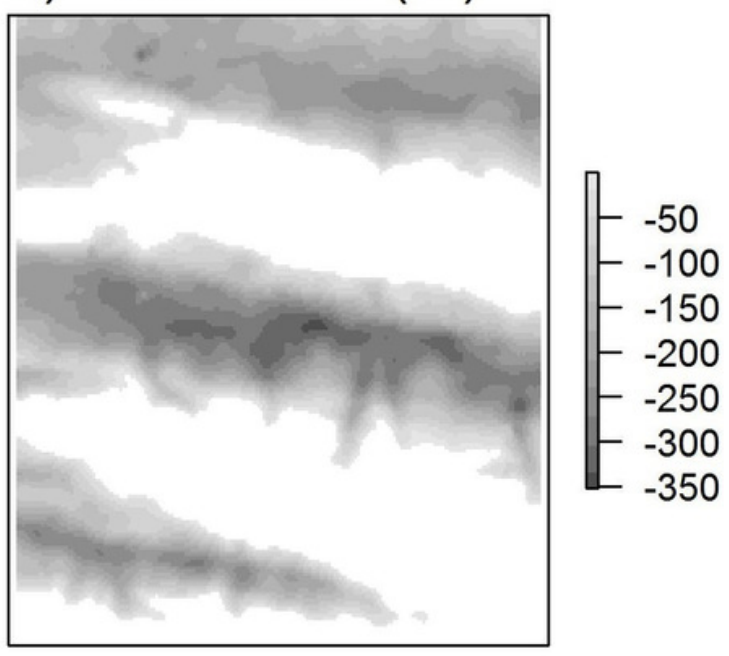

\section{e) CAP likelihood}

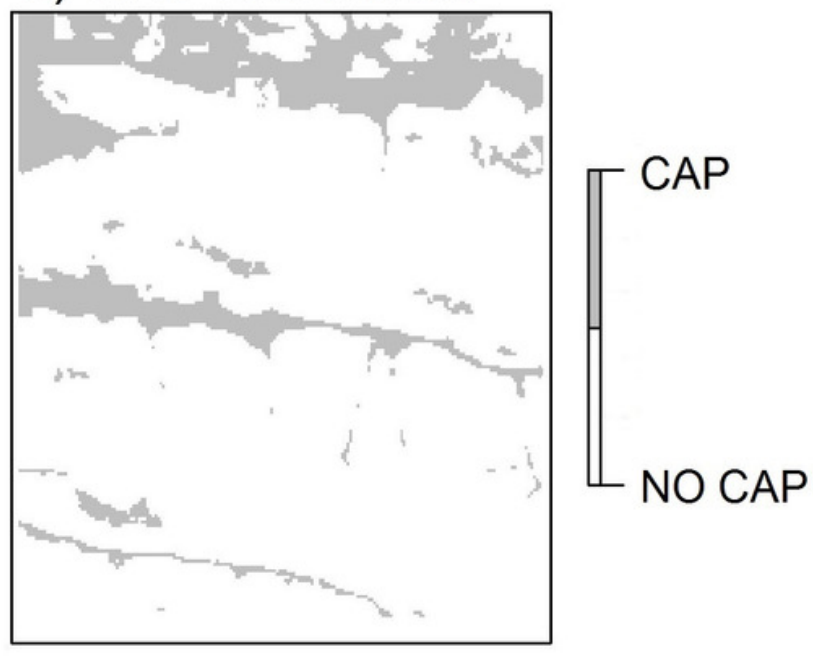


Figure 5

Results of CAP model at calibration valleys in the Zuurberg Mountains

Fig. 5. The naturally occurring biome boundaries between thicket and Karoo shrubland vegetation closely coincide with predictions of frost occurrence at the two calibration valleys (a: Klipfontein; b: Buffels Nek, source Google, 2020, Landsat/Copernicus, AfrigIS PTY (Ltd) 2019). White lines indicate the position of the boundaries between thicket and karoo vegetation. 


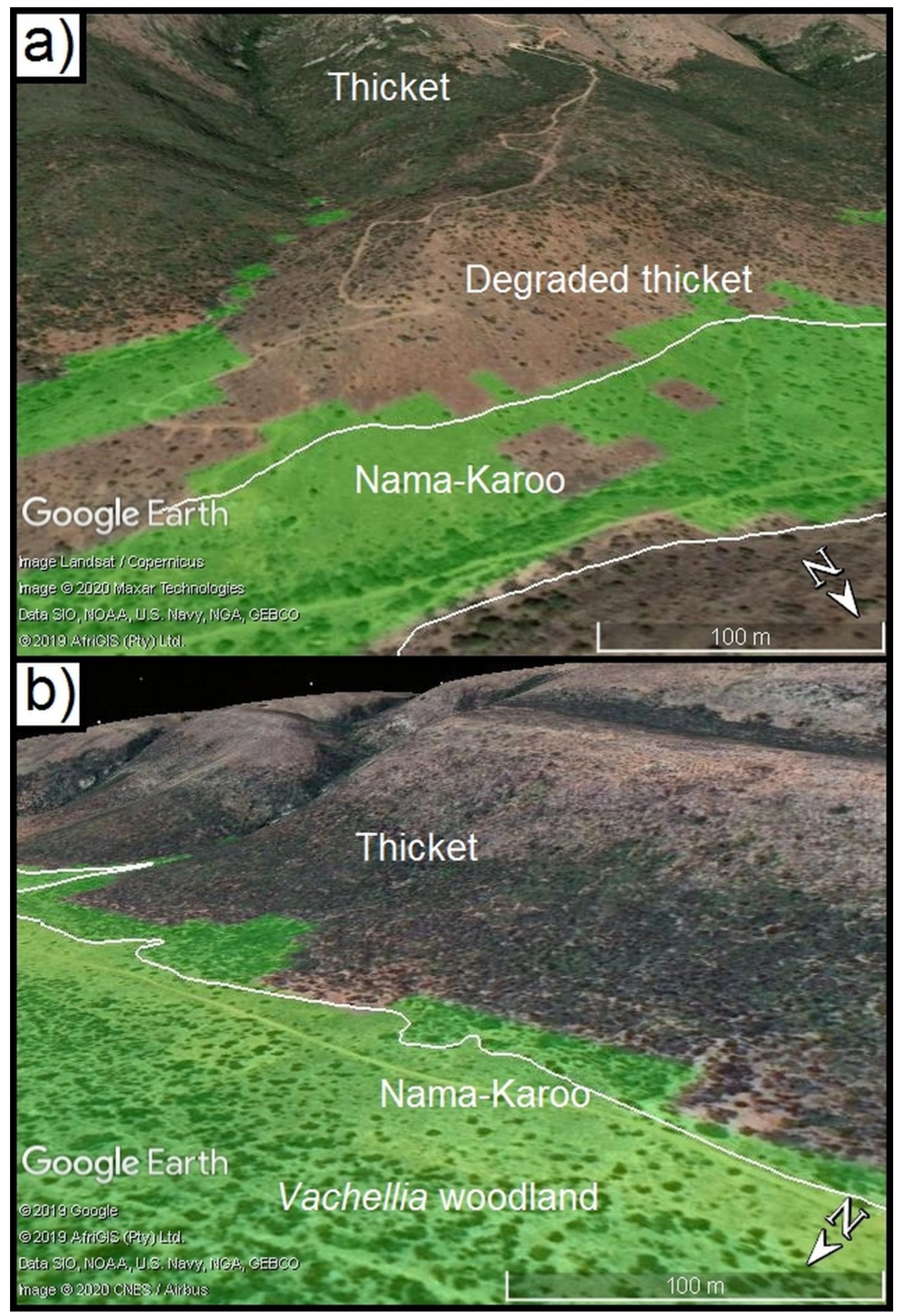


Figure 6

Aboveground NPP rates in the frost-exposed and frost-free TWPs

Fig.6. Differences in plot-level mean aboveground net primary productivity (t.ha- $\left.\mathrm{yr}^{-1}\right)$ of spekboom cuttings in predicted frost-free and frost-prone areas in the 70 plots in the ThicketWide Plot (TWP) experiment (see the Supplementary Information for more details).

Significant differences $(\alpha=0.05)$ were determined using Mann-Whitney U-tests.

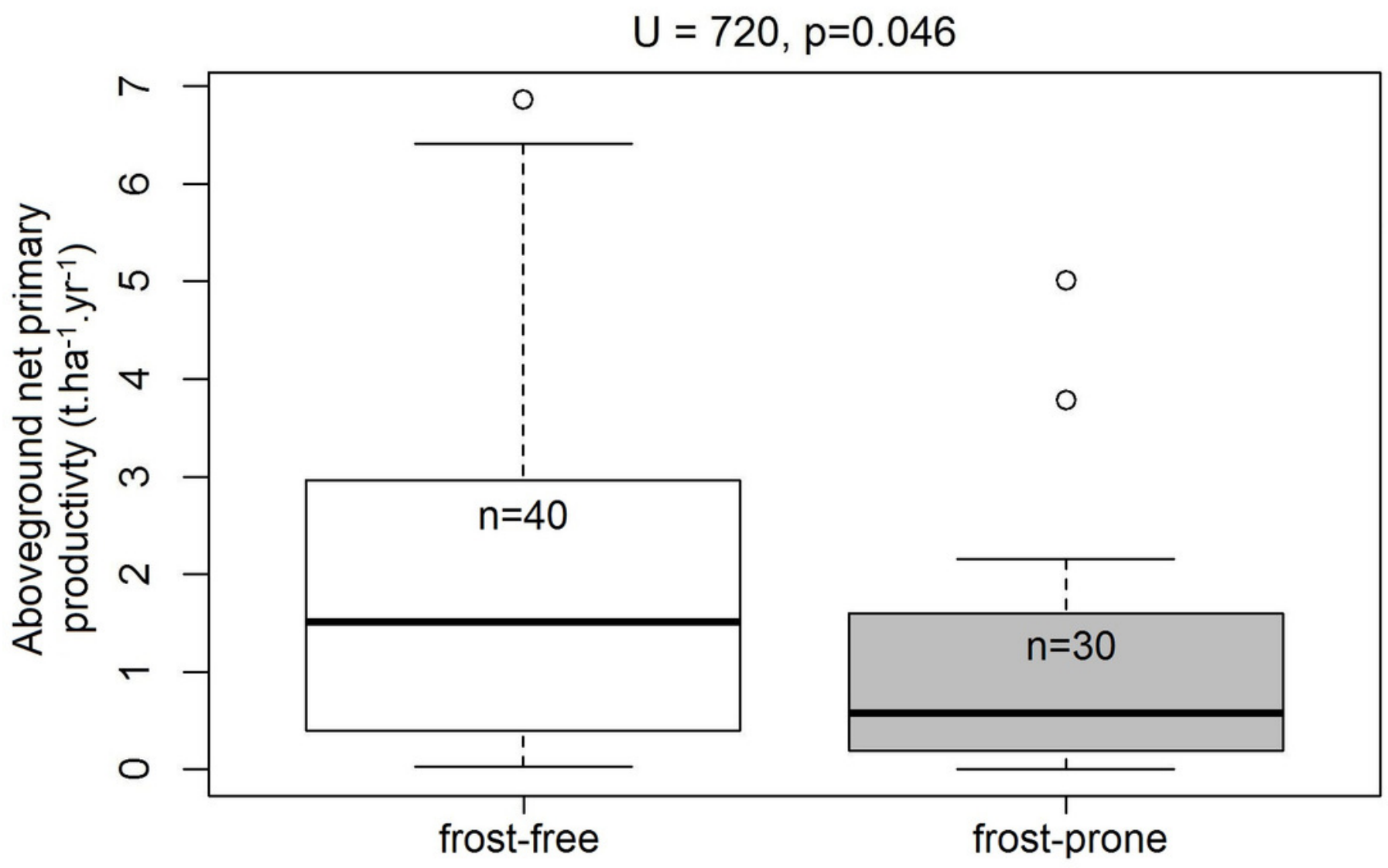

